

\begin{tabular}{|c|c|c|c|}
\hline$\Omega$ & (1] & $\equiv$ & (2) \\
\hline $\begin{array}{l}\text { Rishi Pabary, } \\
\text { Ian M. Balfour-Lynn }\end{array}$ & $\begin{array}{l}\text { Dept of Paediatric } \\
\text { Respiratory Medicine, } \\
\text { Royal Brompton Hospital, } \\
\text { London, UK }\end{array}$ & $\begin{array}{l}\text { Royal Brompton Hospital, } \\
\text { Sydney Street, London, } \\
\text { SW } 3 \text { 6NP, UK }\end{array}$ & i.balfourlynn@imperial.ac.uk \\
\hline
\end{tabular}

\section{Complicated pneumonia in children}

\section{Educational aims}

๑ To understand the pathogenesis of complicated community-acquired pneumonia in children

๑ To gain an understanding into the management of common complications of community-acquired pneumonia in children

\section{Summary}

Community-acquired pneumonia is a common paediatric infection and, even with the introduction of pneumococcal and Haemophilus vaccinations, most children will experience at least one episode before adult life. Most cases are selflimiting but a small number of children will develop sequelae and require hospitalisation. This review focuses on the presentation and management of complications of community-acquired pneumonia in children.

Paediatric community-acquired pneumonia (CAP) is defined as "the presence of signs and symptoms of pneumonia in a previously healthy child due to an infection which has been acquired outside hospital" [1]. Two prospective population-based studies estimate that incidence of CAP is $32.8-33.8$ cases per 10000 children under the age of 5 years or 14.4-14.7 cases per 10 ooo children under the age of 16 years in northern Europe $[2,3]$; the majority of these patients will be managed effectively by primary care, though the threshold for referral and admission to hospital in those less than 6 months of age should be lower [4]. Hospitalisation rates for CAP in children range from $9.5 \%$ to $42 \%$ [5-7] and the median time to resolution of symptoms in children with oxygen saturations of $>85 \%$ at the time of admission is 9 days, regardless of whether treatment is with oral amoxicillin or intravenous benzylpenicillin [8]. A recent British Thoracic Society (BTS) guideline [1] states that severe CAP, as defined by the clinical parameters summarised in table 1 ,
Statement of Interest None declared.
HERMES syllabus link: B.3.3

Paediatric HERMES syllabus link: E.1, E.2 


\begin{tabular}{|c|c|c|}
\hline Respiratory rate breaths $\cdot \mathrm{min}^{-1}$ & $>70$ & $>_{50}$ \\
\hline Respiratory distress & $\begin{array}{l}\text { Moderate-severe recession } \\
\text { Nasal flaring } \\
\text { Cyanosis } \\
\text { Grunting } \\
\text { Intermittent apnoea }\end{array}$ & $\begin{array}{l}\text { Unable to complete sentences } \\
\qquad \begin{array}{c}\text { Nasal flaring } \\
\text { Cyanosis } \\
\text { Grunting }\end{array}\end{array}$ \\
\hline Feeding & Unable to feed & Signs of dehydration \\
\hline
\end{tabular}

is more likely to be complex and require hospitalisation. The focus of this review is on complicated pneumonia, which develops only in a small proportion of immunocompetent children who have no other underlying diagnosis, such as chronic suppurative lung disease; for management of simple CAP in children, we advise the reader to refer to the BTS guideline [1].

While most paediatric CAP will be managed in primary or secondary care, complications may necessitate referral to a tertiary centre. The overall complication rate in a recent BTS Paediatric Pneumonia Audit was $7.1 \%$ from 2200 cases in 77 hospitals, with empyema in $4.4 \%$ and lung abscess in $0.9 \%$ of children [9].

\section{Persistent pneumonia}

Streptococcus pneumoniae is the most common bacterial cause of CAP in children [10, 11] and significant clinical improvement is expected in the first $24-48 \mathrm{~h}$ after starting empirical treatment with a $\beta$-lactam [12]. Failure to respond may indicate that the causative organism is not sensitive to initial therapy; Staphylococcus aureus, and in particular the toxin-producing Panton-Valentine leukocidin (PVL) strain [13], or atypical organisms, such as Mycoplasma pneumoniae or Fusobacterium necrophorum [14], may cause severe or persistent symptoms. Equally, monotherapy with macrolides may also lead to treatment failure due to emergence of resistant strains of S. pneumoniae $[15,16]$ and therefore first-line treatment of severe CAP in our centre is always with both a $\beta$-lactam (usually intravenous co-amoxiclav) and a macrolide (usually oral azithromycin); it has been demonstrated that this regimen reduces mortality in adults hospitalised patients with CAP [17].

The BTS states that oxygen saturation $<92 \%$ in air in older children is a cardinal sign of severe CAP [1]; only a small number of these children will develop respiratory failure or septic shock and require mechanical ventilation on a paediatric intensive care unit (PICU) and, even then, survival in previously healthy children is excellent in developed countries. Mortality figures in England and Wales (UK) in 2011 estimate that only $0.01 \%$ of deaths in children aged $\geqslant 14$ years were attributable to pneumonia. The total number of deaths caused by pneumonia across all age groups in 2011 was 25696 [18], reflecting the fact that there are co-existing morbidities in the adult population, while most cases in children are secondary to infection in a previously healthy lung. However, as illustrated in table 2, even in developed countries, one child per week dies from pneumonia.

\section{Systemic complications}

\section{Severe sepsis}

Severe sepsis is defined as a systemic inflammatory response in the presence of infection with end-organ dysfunction [19]. Septic shock occurs when there is cardiovascular dysfunction, which usually necessitates 
admission to a PICU for intravenous inotropic support [20]. The incidence of this in children presenting with CAP is unclear but from our experience, even in children who present with empyema or necrotising pneumonia, it is very low. A large adult study suggests that severe sepsis is a common feature in CAP ( $48 \%$ of hospitalised patients) with $4.5 \%$ of patients developing septic shock [21].

\section{Acute respiratory distress syndrome}

The recent Berlin Consensus defines acute respiratory distress syndrome (ARDS) as severe hypoxaemia refractory to supplemental oxygen therapy that usually occurs within $72 \mathrm{~h}$ of an acute inflammatory lung injury that increases vascular permeability and decreases lung compliance [22]. ARDS can be categorised as mild, moderate or severe and bilateral radiographic opacities are typically present. Pneumonia and septic shock can both lead to ARDS and these children will typically require conventional mechanical or high-frequency oscillation ventilation, both of which can accentuate the systemic inflammatory response by the mechanisms summarised in figure 1 [23]. Published mortality rates from ARDS vary from $10 \%$ to $90 \%[24,25]$ with most deaths secondary to the underlying cause of acute lung injury (sepsis, trauma or burns) rather than primary respiratory failure; our experience is that this is an extremely rare occurrence secondary to CAP.

\section{Syndrome of inappropriate antidiuretic hormone secretion}

The syndrome of inappropriate antidiuretic hormone secretion is characterised by excessive

TABLE 2 Mortality in children aged $<14$ years for England and Wales (UK), 2011

\begin{tabular}{lccc} 
& \multicolumn{3}{c}{ Age years } \\
\cline { 2 - 4 } & $<1$ & $\mathbf{1 - 4}$ & $\mathbf{5 - 1 4}$ \\
\hline Total deaths & 3154 & 516 & 547 \\
\hline $\begin{array}{l}\text { Respiratory } \\
\text { causes }\end{array}$ & 77 & 55 & 49 \\
\hline $\begin{array}{l}\text { Pneumonia } \\
\text { Data are presented as } \mathrm{n} \text { and are from [18]. }\end{array}$
\end{tabular}

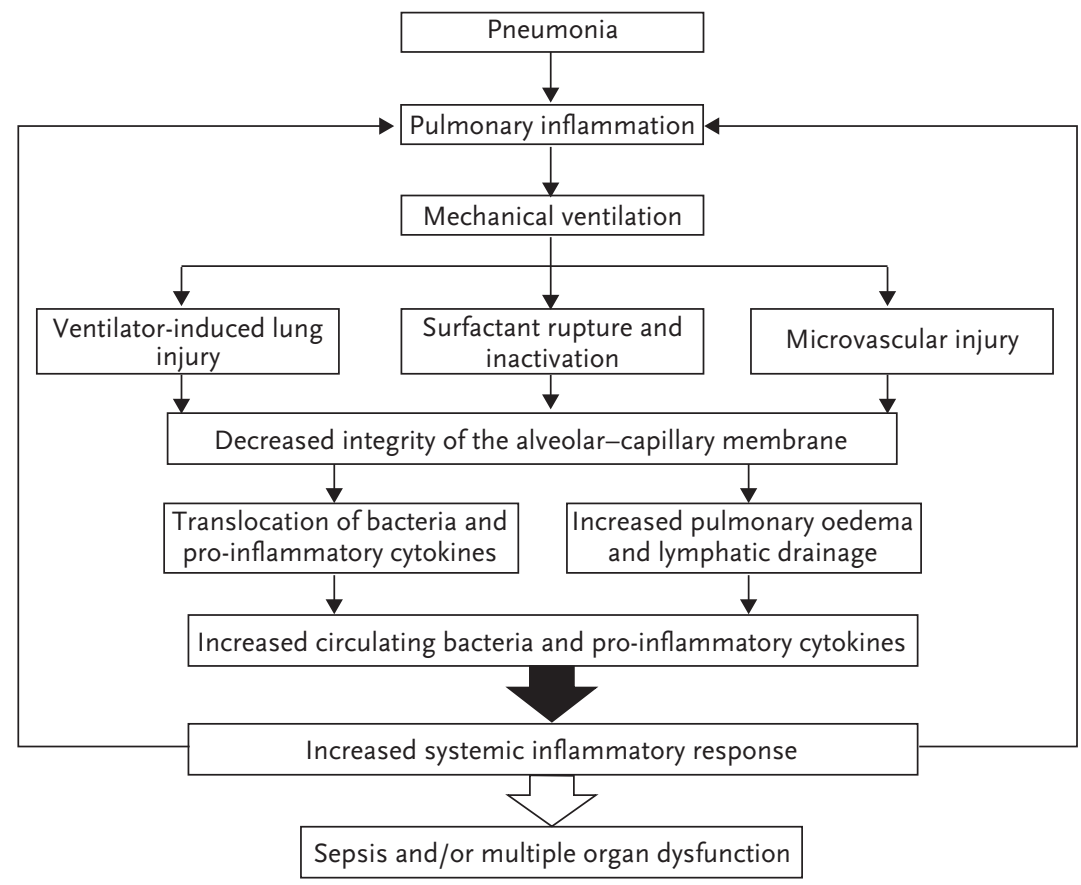

Figure 1

Proposed mechanism of exacerbation of the systemic inflammatory response secondary to mechanical ventilation. Reproduced and modified from [23] with permission from the publisher.

release of antidiuretic hormone from the posterior pituitary gland leading to dilutional hyponatraemia. It occurs in around one-third of children hospitalised with CAP [26], the mechanism for which remains unclear, and is associated with higher inflammatory markers [27] and poorer outcomes [26]. Severe hyponatraemia can cause confusion or seizures and for this reason fluid restriction (between 50\% and 66\% of maintenance) is recommended in children with CAP and hyponatraemia who are haemodynamically stable and not dehydrated [28].

\section{Haemolytic uraemic syndrome}

Haemolytic uraemic syndrome (HUS) is one of the main causes of acute renal failure in the paediatric population [29] and has been described following invasive S. pneumoniae infection. These cases of "atypical" HUS have a much higher morbidity and mortality than those due to typical organisms such as enterotoxigenic Escherichia coli O157 [30, 31]. HUS should always be suspected early in cases of CAP associated with anaemia, thrombocytopenia and renal dysfunction (anuria) as $75 \%$ of these cases are likely to require dialysis [30] and early intervention may be associated with better outcome [32]. 


\section{Disseminated intravascular coagulation}

Disseminated intravascular coagulation (DIC) is a consumptive coagulopathy that can present secondary to infection with S. pneumoniae [33] or M. pneumoniae [34]. Like HUS, thrombocytopenia and anaemia are present but renal dysfunction is secondary to acute tubular necrosis rather than the thrombotic microangiopathy of the renal vasculature, that is seen in HUS [30]. Activated partial thromboplastin time and prothrombin time are prolonged in DIC while fibrinogen is reduced; these are all essentially within normal limits in HUS.

\section{Secondary thrombocytosis}

The importance of platelets in the host immune response is increasingly recognised [35] and it has been demonstrated in adults that secondary thrombocytosis, which has until recently been considered a normal inflammatory response to infections, is associated with respiratory complications of CAP (pleural effusion and empyema) and poorer outcomes [36]. Platelet counts may therefore be of prognostic value in paediatric CAP, though there is no role for antiplatelet treatment [?].

\section{Pulmonary complications}

Treatment failure may be due to antibiotic resistance (or atypical organisms such as Mycobacterium tuberculosis being only partially sensitive to empirical therapy) or because CAP is the first presentation of an underlying condition such as cystic fibrosis, immunodeficiency or congenital thoracic malformation (CTM). However, it is more usually because pulmonary complications to the initial infection have developed; these can be divided into 1) those that are due to the accumulation of fluid, 2) those that are due to accumulation of air or 3) atelectasis.

\section{Parapneumonic effusion/empyema}

Injury to the lung parenchyma due to infection can lead to increased capillary permeability and accumulation of fluid in the pleural space, which happens in three distinct stages. In the early stages of infection, fluid is serous and sterile (exudative stage) but over time, typically $1-2$ weeks, there is an influx of white blood cells and bacteria (fibropurulent stage), leading to pus formation (empyema). Over 2-4 weeks after the primary infection, fibrin is deposited on the pleural surfaces and the fluid collection becomes organised, leading to a loculated empyema composed of separate pockets of viscous fluid. Around $0.7 \%$ of children hospitalised with CAP will develop empyema [37] and, in cases where a causative organism is isolated (in around $37.7-58.5 \%$ of cases [38] with standard microbiological techniques), S. pneumoniae (primarily serotype 1) accounts for $68 \%$ [39]. The incidence of childhood empyema was increasing prior to the introduction of the heptavalent pneumococcal conjugate vaccine (PCV-7) into the standard childhood immunisation schedule in 2006 [40, 41]. Although it has been reported that incidence decreased 22\% between 2006 and 2008 [42], and those due to serotypes covered by PCV-7 declined completely from $48 \%$ of cases, the UKESPE study reports that there was an increase in disease caused by other serotypes [39]. Of particular concern is an increased UK prevalence of disease caused by serotype 19a [43], which has been associated with a greater likelihood of PICU admission and mortality [43-45], and serotype 3, which is able to resist phagocytosis $[46,47]$ and has been associated with increased incidence of bronchopulmonary fistula [48]. Although both these serotypes are covered by the new PCV-13 vaccination, it remains to be seen whether other serotypes will subsequently become more prevalent (the socalled replacement phenomenon) and what effect this will have on ongoing complication rates of CAP.

Pleural effusion or empyema should be considered if a child does not respond to $48 \mathrm{~h}$ treatment with intravenous antibiotics

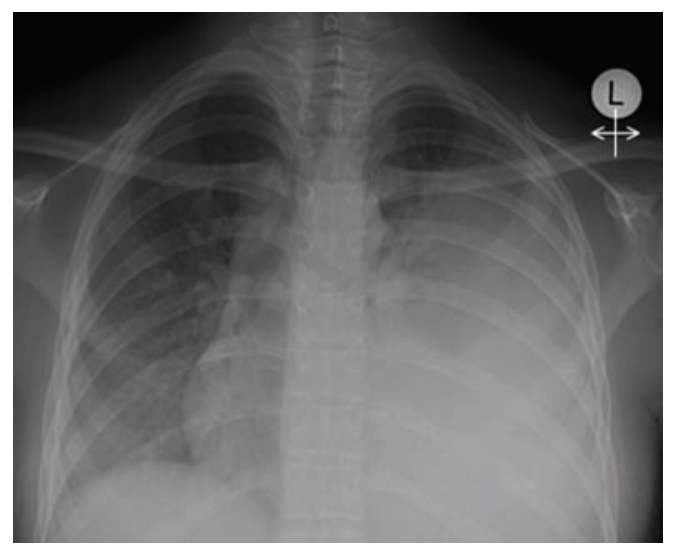

Figure 2

Left-sided pleural effusion. 

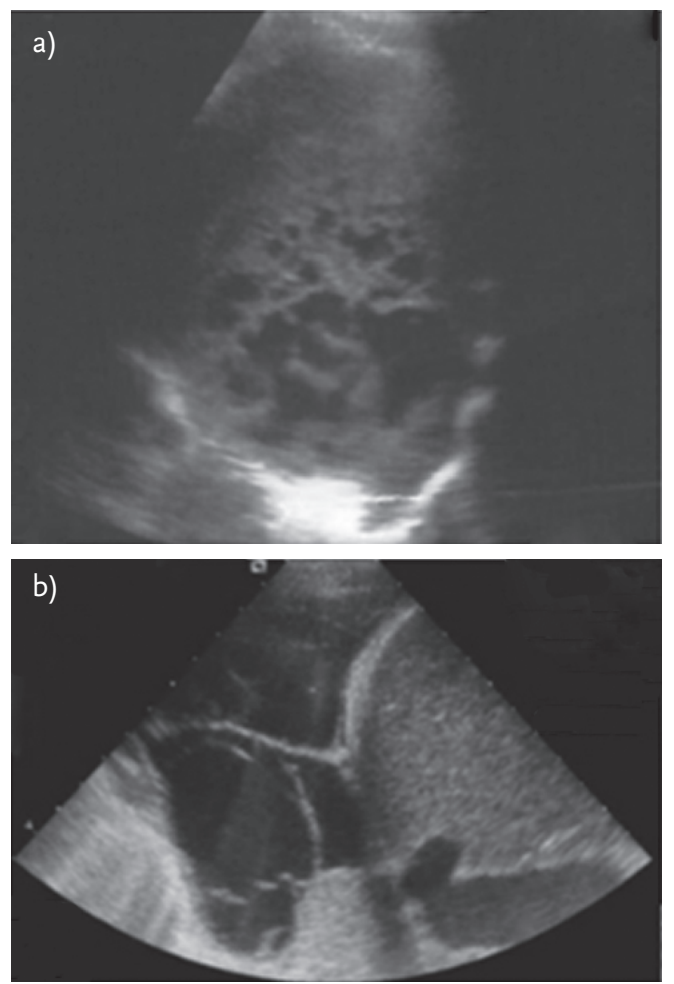

Figure 3

Thoracic ultrasound scans showing loculated pockets of fluid.

[49]. They are diagnosed on the basis of clinical signs, such as decreased air entry and dullness to percussion over the affected area [50], and may be confirmed by plain chest radiograph (fig. 2), although can be difficult to distinguish from consolidation alone. Thoracic ultrasound is essential to determine the extent and nature of fluid collections (fig. 3) although there is debate as to whether this is useful in predicting outcome [51, 52]. Differentiation of solid and cystic areas in the pleural cavity is poor with ultrasound and, if there is any doubt about the diagnosis (for example, the onset of symptoms was insidious and inflammatory markers are only moderately elevated, raising the possibility of malignancy), computed tomography (CT) should be performed prior to making any further decisions on management [53]. Although CT should not be undertaken routinely $[1,37]$, its utility in certain situations is illustrated in figure 4 , which shows bilateral empyema but also Burkitt's lymphoma that was not evident on ultrasound.

In general, effusions $<2 \mathrm{~cm}$ in depth can initially be managed conservatively, as drainage is technically difficult and resolution may occur with intravenous antibiotics alone.
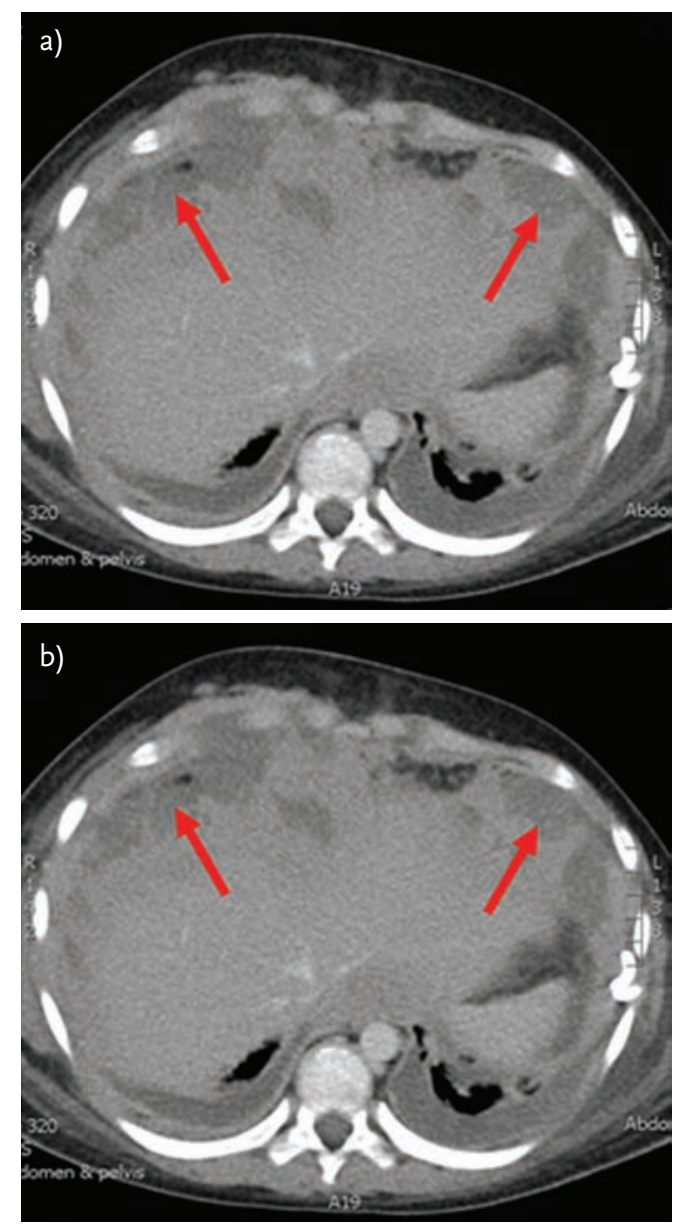

\section{Figure 4}

CT image showing bilateral empyema in association with Burkitt's lymphoma. Red arrows point to areas of lymphoma.

For larger effusions or if there is significant respiratory distress, oxygen requirement or mediastinal shift, patients should be referred to a tertiary paediatric respiratory centre for assessment with or without insertion of a chest drain [49]. In our centre, chest drainage is performed using soft pigtail catheters (French gauge 6-10) (fig. 5) inserted under general anaesthesia with ultrasound guidance; this approach is felt to reduce patient trauma and permit early mobilisation as the small drains are minimally intrusive. Rapid drainage by thoracocentesis is not recommended due to the risk of re-expansion pulmonary oedema [54, 55] and drains should be clamped for $1 \mathrm{~h}$ if $\geqslant 10 \mathrm{~mL} \cdot \mathrm{kg}^{-1}$ of fluid drains from a chest tube in any 6o-min period [49]. Serial thoracocentesis of small aliquots of fluid is not indicated in children as this either increases trauma if done under local anaesthesia or requires repeated general 

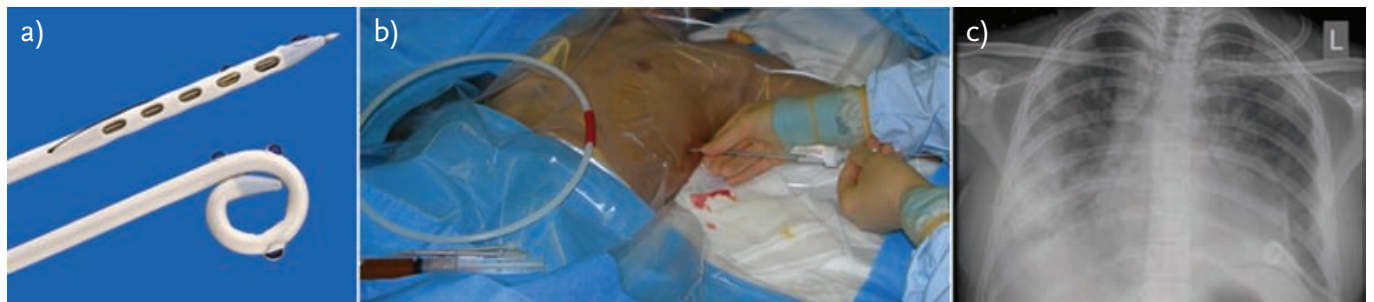

Figure 5

a) Small-bore pigtail catheter. b) Insertion of chest drain using aseptic Seldinger technique. c) Post-procedure radiograph with drain in situ. This patient had rapid drainage of fluid following drain insertion and developed ARDS, most likely due to re-expansion pulmonary oedema.

anaesthesia. In cases where drainage is slow, due to the fluid being thick or loculated, twice-daily intrapleural fibrinolytics such as urokinase have been shown to reduce duration of hospital stay [52], incidence of residual pleural thickening [56] and allow resolution of empyema without surgical intervention in up to $93 \%$ of cases [52]. Although in one small study, the failure rate was reported at almost $70 \%$ [57], in our experience, in 180 children with empyema who required chest drains between 2002 and 2007, of whom 80\% received intrapleural urokinase, $<3 \%$ went on to have a surgical procedure. Chest tubes are removed when $\leqslant 50 \mathrm{~mL}$ per day is draining and the integrity of the drain is confirmed; chest radiographs should be repeated 3-4 $\mathrm{h}$ after drain removal to ensure that re-accumulation or pneumothorax has not occurred.

Adult studies of fibrinolytics in empyema are less convincing, probably due to underlying comorbidities and a higher incidence of noninfective causes. Around $33 \%$ of adults eventually require surgical intervention [58] and mortality rates are significantly higher [59, 60]. The First Multicenter Intrapleural Sepsis Trial (MIST1) found that intrapleural streptokinase did not reduce mortality, surgical rates or duration of hospital stay [58]. A subsequent trial of intrapleural tissue plasminogen activator (tPA) and recombinant human DNase (rhDNase) demonstrated significant improvements in pleural opacities on chest radiography and reduction in both the surgical referral rate and duration of hospital stay in adult patients randomised to receive both treatments, with no difference seen with either treatment alone or double-placebo [61]. As yet, there have been no studies in children investigating combination therapy; the presumed mechanism of action of intrapleural rhDNase is that it breaks down extracellular DNA in the pleural space, thus reducing fluid viscosity and enhancing drainage, which is equally valid in the paediatric population and, therefore, merits further investigation.

Primary surgical management of childhood empyema is usually via a mini-thoracotomy or video-assisted thoracoscopic surgery (VATS). Both approaches remove pus and fluid from the pleural space and reduce the need for open drainage and decortication $[62,63]$, and are associated with reduced morbidity compared to open thoracotomy $[63,64]$. However, children who undergo surgery still require a chest drain post-operatively and there is debate as to whether there is any reduction in hospital stay [65-67] compared with nonsurgical management. Two prospective randomised studies comparing VATS with chest drains plus intrapleural fibrinolytics found no difference in treatment failure rate $[66,68]$ and, although VATS failure rates in a subsequent study undertaken in a different centre were significantly better (7\%) [69], the additional expense $[68,70]$ and limited availability [69] of VATS suggest that it should currently be considered as a second-line treatment option.

Following successful drainage, low-grade fever may persist but is not a contraindication to discharge provided that the trend is downwards and there is clinical improvement, which can be confirmed by repeating inflammatory marker tests. Children are discharged home on oral antibiotics (usually 2-4 weeks of co-amoxiclav with or without an additional agent on the basis of clinical/ microbiological findings) with outpatient follow-up and repeat chest radiography after 6-8 weeks. Radiological findings generally normalise over time and parents should be advised that there should be no long-term sequelae in previously healthy children but to seek urgent medical attention for further investigation if there is any recurrence of 
symptoms. For more detailed recommendations on the management of pleural infection in children, refer to the BTS guideline [49].

\section{Pericardial effusion}

Accumulation of fluid between the heart and the pericardial sac, or pericardial effusion, is rare in childhood but may co-exist with parapneumonic effusion, particularly left-sided cases, simply due to the proximity of the pleura and pericardium [71, 72]. Most of these associated pericardial effusions improve with treatment of the underlying infection but urgent echocardiography should be considered in cases of haemodynamic compromise as pericardiocentesis may be required [73].

\section{Lung abscess}

Lung abscesses are thick-walled cavities $(\geqslant 2 \mathrm{~cm})$ containing purulent material that are the result of acute destruction of the lung parenchyma following inflammation, necrosis and cavitation [74]. They are rare and mainly seen in children with respiratory co-morbidities $[75,76]$ or neurodevelopmental abnormalities who are at increased risk of recurrent aspiration [77] but may be primary, occurring as sequelae of CAP. With the advent of interventional radiology, causative organisms in lung abscess can be isolated in around twothirds of cases [78], with Gram-positive cocci (S. pneumoniae, S. aureus and Streptococcus pyogenes) and, rarely, M. pneumoniae [79] associated with primary forms, and Gramnegative anaerobes more likely in abscesses secondary to other underlying conditions.

Symptoms of primary lung abscess in children include fever, cough, dyspnoea and chest pain; there may be localised reduction in air entry and crackles on auscultations of the chest as well as dullness to percussion, and, hence, there is overlap with the presentation of uncomplicated CAP, although the evolution of lung abscesses is often more insidious [77]. Chest radiography may show a thick-walled cavity with an air-fluid level but misses the diagnosis in around $20 \%$ of cases [80] and may not distinguish an abscess from underlying congenital thoracic abnormalities or consolidation alone; thus, contrastenhanced CT is the investigation of choice, particularly as it can help to guide percutaneous diagnostic aspiration with or without drainage $[77,80]$. Although ultrasound has a role in differentiating loculated empyema and lung abscess, it is most useful as a tool for monitoring the response to treatment with no associated exposure to radiation.

The mainstay of treatment of primary lung abscess has traditionally been intravenous penicillin for 2-3 weeks followed by a further 4-8 weeks of oral antibiotics [81]; our centre occasionally adds clindamycin to provide additional cover for $S$. aureus or metronidazole for anaerobic cover, and resolution in most children will occur with medical management alone [82]. The course of disease may be prolonged and fungal infections such as aspergilloma should be considered if there is a poor response to antibiotics. Surgical intervention has, in the past, been associated with significant morbidity [77, 83] and was recommended as an intervention only if prolonged medical therapy was unsuccessful [84] or if there was respiratory compromise, such as mediastinal shift, necessitating mechanical ventilation. However, two recent reports suggest that insertion of a pigtail catheter at the time of presentation and initial CT-guided percutaneous aspiration [77] or thoracoscopic drainage [85] can significantly reduce duration of hospital stay and antibiotic therapy, but this has yet to be confirmed by larger studies. It is estimated that $90 \%$ of children with primary lung abscess will respond to medical management and make a full recovery although empyema, pneumothorax and bronchopulmonary fistulae (defined as an abnormal connection between the pleural space and bronchial tree) are recognised sequelae [74]. Outpatient follow-up should be arranged and consideration given to the possibility that the lung abscess was a primary presentation of an undiagnosed CTM that became secondarily infected. An example of a right upper lobe lung abscess, which are typically seen following aspiration, and its evolution over time is shown in figure 6 .

\section{Necrotising pneumonia}

An increasingly recognised sequela of paediatric CAP is necrotising or cavitary pneumonia, which was first described in 1994 [86, 87] and has recently been shown to complicate up to $20 \%$ of childhood empyema [88]. It is characterised by necrosis and liquefaction of lung parenchyma, which is thought to be secondary to ischaemia caused by thrombosis of intrapulmonary vessels and can culminate 

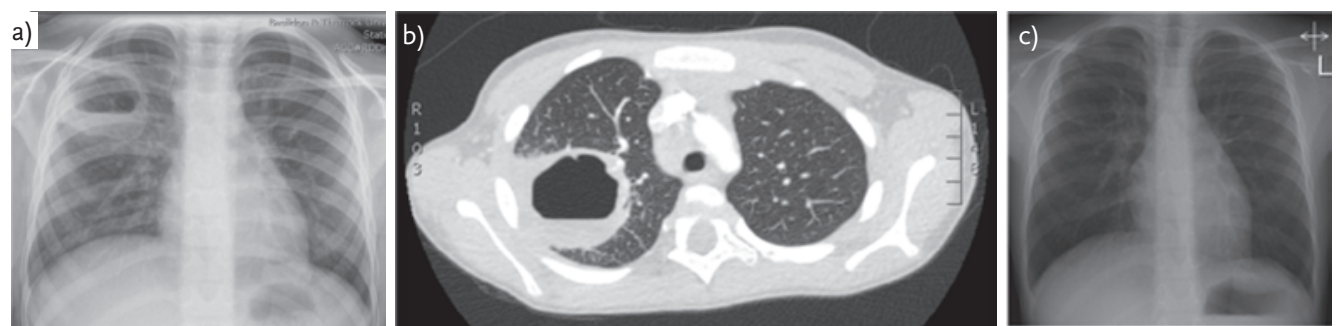

Figure 6

Right upper lobe lung abscess on a) plain chest radiography and b) CT. c) Good resolution in follow-up radiograph after 6 weeks of antibiotic therapy.

in pulmonary gangrene [89] of single or multiple lobes [74, 90]. Historically, the primary causative pathogen was thought to be S. aureus [91] but S. pneumoniae, particularly serotypes $1,39 \mathrm{~V}$ and $14[88,89]$, is now the predominant cause, although M. pneumoniae [92], methicillin-resistant S. aureus and PVL strains of $S$. aureus [93] have also been implicated. Diagnosis is usually made on CT, as plain chest radiographs will not accurately demonstrate the typical disruption of normal parenchymal architecture where multiple airor fluid-filled cavities replace the normal lung tissue [90]. Air-filled cavities (pneumatocoeles) are common in necrotising pneumonia as one-way passage of air into the peripheral airways occurs following necrosis of bronchioles and alveoli [74]; if they arise towards the periphery of the parenchyma, pneumatocoeles may lead to pneumothorax. Where necrosis occurs adjacent to the pleura, a bronchopleural fistula may form, resulting in pneumothorax or pyopneumothorax.

Necrotising pneumonia is usually accompanied by severe sepsis and prolonged courses of intravenous antibiotics are necessary. Chest
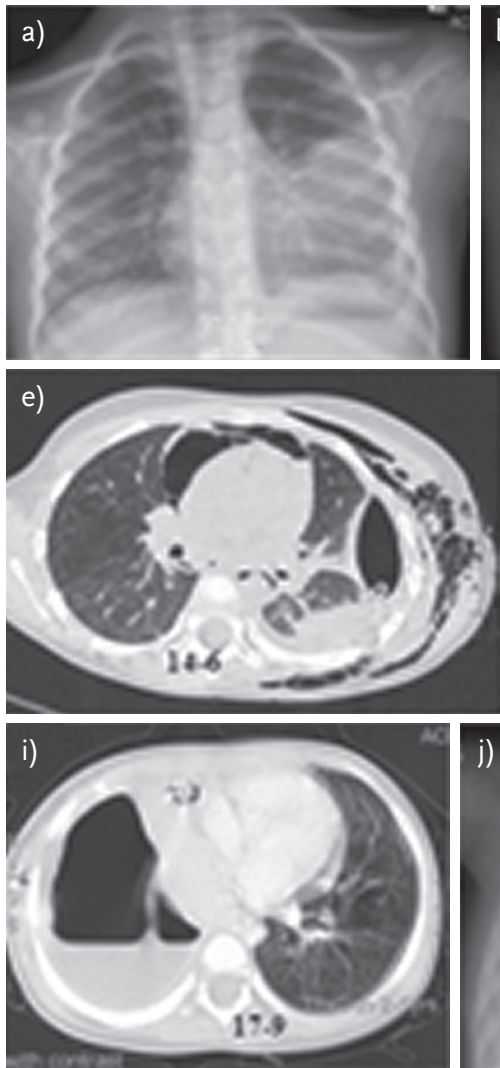
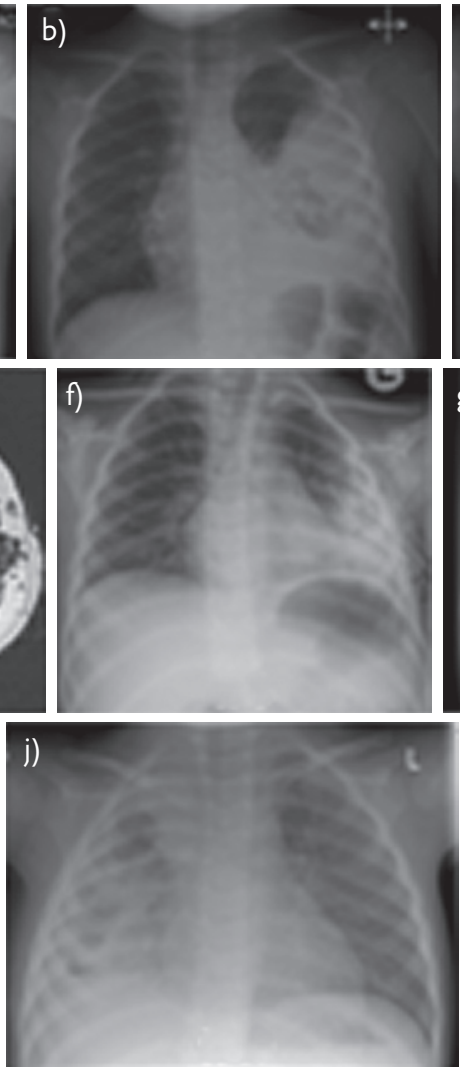
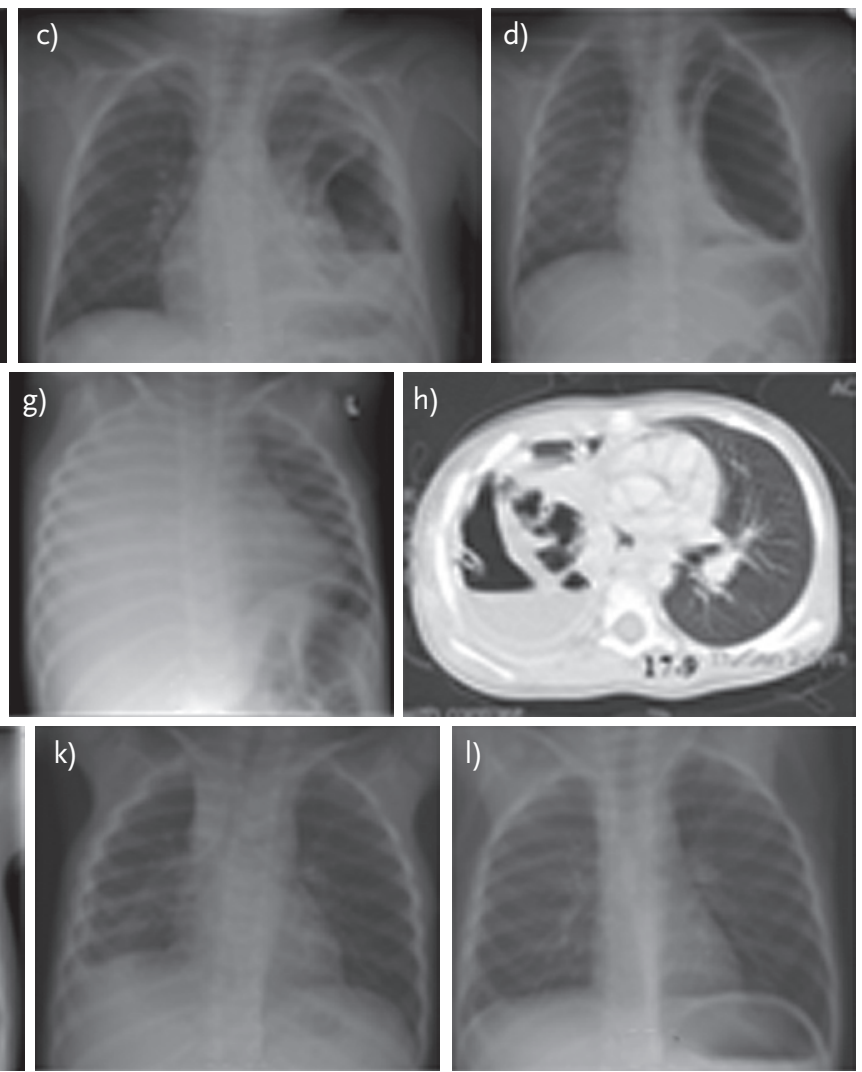

Figure 7

Prolonged course of necrotising pneumonia caused by Streptococcus pneumoniae. a) Chest radiography (CXR), day 1; b) CXR, day 4; c) CXR, day 8; d) CXR, day 17; e) CT, day 22; f) CXR, day 27; g) CXR, day 99; h) CT, day 116; i) CT, day 144; j) CXR, day 144; k) CXR, day 178; l) CXR, day 298. 
Cause

Aspiration (silent)
Gastro-oesophageal reflux disease

Bronchiectasis

Immunodeficiency

Cystic fibrosis

Primary ciliary dyskinesia

Congenital heart disease

drains may need to be in situ for many weeks due to persistent air leaks from bronchopulmonary fistulae; in order to minimise the risk of obstruction, our centre recommends larger and stiffer drains than for empyema, as significant volumes of air can accumulate rapidly following blockage, with subsequent lung collapse. Fibrinolytics are not used as they may impair healing of pleural holes. Longterm outcome with conservative management is good, with a mortality rate of $5.5 \%[87,94]$, although one series reported that $66 \%$ of children required thoracotomy for decortication, bronchopulmonary fistula repair or partial pneumonectomy [94]. Healing of the fistula may be promoted by excising the parietal pleura, which encourages adherence of the lung to the chest wall. In our opinion, patience is paramount and the more invasive surgical option of muscle flap thoracoplasty should only be used as a last resort as it is technically difficult and, because grafts permanently reduce vital capacity, associated with significant morbidity post-operatively [95]. Figure 7 shows serial radiographs from a child with necrotising pneumonia due to pneumococcal infection; the course is prolonged and pneumatocoeles are prominent.

\section{Atelectasis}

Acute atelectasis is defined as collapse of part or all of one lung. It was historically considered to be due to alveolar deflation but evidence is now emerging that it is due to accumulation of alveolar fluid [74]. It can occur secondary to mucus plugging in CAP, suggesting that chest physiotherapy may be

\section{Investigation}

Video fluoroscopy

$\mathrm{pH} /$ impedance study with or without milk scan

High-resolution chest $\mathrm{CT}$ with or without contrast

Immunoglobulins and vaccine responses

Sweat test and genetic analysis

Nasal nitric oxide \pm ciliary brushings

Echocardiogram useful, although there is little evidence to support this [96] and a Cochrane Review is currently being undertaken. Flexible bronchoscopy, both as a diagnostic and therapeutic intervention, has been shown to be beneficial in atelectasis associated with infections in children [97].

\section{Further investigations and follow-up}

In our centre, we recommend that all patients with complicated CAP be followed up as outpatients until there is complete resolution on chest radiography. If there is chronic atelectasis on the chest radiograph, other causes such as airway compression by lymph nodes (as seen in tuberculosis and malignancy) or an inhaled foreign body should be considered.

Flexible bronchoscopy may reveal luminal blockage, compression or narrowing (bronchomalacia), and should be considered in complicated CAP where there is a prolonged course. Furthermore, any child who has more than one episode of complex CAP confirmed by radiography should be fully investigated to seek an underlying cause; first-line investigations that are undertaken in our centre and summarised in table 3 .

The final point to consider is that respiratory infections do not always reflect a primary underlying pulmonary pathology. A child with recurrent CAP was recently referred to our centre for respiratory investigations, which were all entirely unremarkable. Echocardiography subsequently revealed an atrial septal defect and the patient had full resolution of symptoms following surgical closure. 


\section{Educational questions}

Which of the following statements is/are true?

1) In severe CAP,

a) Staphylococcus aureus is the most common causative organism

b) Hypernatraemia can result due to the syndrome of inappropriate antidiuretic hormone secretion

c) If acute respiratory distress syndrome (ARDS) develops, bilateral radiological signs are usually present

d) Mortality from ARDS usually occurs due to primary respiratory failure

e) Haemolytic uraemic syndrome caused by Streptococcus pneumoniae is associated with higher morbidity and mortality than cases that are due to Escherichia coli

\section{2) In paediatric} empyema,

a) there are three pathological stages (exudative, fibropurulent and organisational)

b) incidence of has fallen since introduction of pneumococcal vaccination

c) S. pneumoniae serotype 19a is associated with bronchopulmonary fistula

d) computed tomography is a first-line investigation that is used to guide thoracocentesis

e) no more than $10 \mathrm{~mL} \cdot \mathrm{kg}^{-1}$ of fluid should be drained within any 6o-min period

\section{3) Lung abscesses}

a) are more common in children with neurodevelopmental abnormalities

\section{References}

1. Harris M, Clark J, Coote N, et al. British Thoracic Society guidelines for the management of community acquired pneumonia in children: update 2011 . Thorax 2011; 66: Suppl. 2, ii1-ii23.

2. Senstad AC, Suren P, Brauteset L, et al. Communityacquired pneumonia (CAP) in children in Oslo, Norway. Acta Paediatr 2009; 98: 332-336.

3. Clark JE, Hammal D, Hampton F, et al. Epidemiology of community-acquired pneumonia in children seen in hospital. Epidemiol Infect 2007; 135: 262-269.

4. Jadavji T, Law B, Lebel MH, et al. A practical guide for the diagnosis and treatment of pediatric pneumonia. CMAJ 1997; 156: S703-S711.

5. Bunuel Alvarez JC, Vila Pablos C, Tresserras Gonzalez E, et al. Estudio descriptivo de la neumonia adquirida en la comunidad en la edad pediatrica. Una perspectiva desde atencion primaria. $[A$ descriptive study of community-acquired pneumonia in childhood. A primary care perspective]. Aten Primaria 1999; 23: 397-402.

6. Jokinen $\mathrm{C}$, Heiskanen L, Juvonen $\mathrm{H}$, et al. Incidence of community-acquired pneumonia in the population of four municipalities in eastern Finland. Am J Epidemiol 1993; 137: 977-988.

7. Maclntyre CR, Mclntyre PB, Cagney M. Communitybased estimates of incidence and risk factors for childhood pneumonia in Western Sydney. Epidemiol Infect 2003; 131: 1091-1096.

8. Atkinson M, Lakhanpaul M, Smyth A, et al. Comparison of oral amoxicillin and intravenous benzyl penicillin for community acquired pneumonia in children (PIVOT trial): a multicentre pragmatic randomised controlled equivalence trial. Thorax 2007; 62: 1102-1106.

9. Thomson A. British Thoracic Society Paediatric Pneumonia Audit 2010/11. Report2011. www.britthoracic.org.uk/audit.aspx Date last updated: January 22, 2013.

10. Heiskanen-Kosma T, Korppi M, Jokinen C, et al. Etiology of childhood pneumonia: serologic results of a prospective, population-based study. Pediatr Infect Dis J 1998; 17: 986-991.

11. Michelow IC, Olsen K, Lozano J, et al. Epidemiology and clinical characteristics of community-acquired pneumonia in hospitalized children. Pediatrics 2004; 113: 701-707.

12. Toikka P, Virkki R, Mertsola J, et al. Bacteremic pneumococcal pneumonia in children. Clin Infect Dis 1999; 29: 568-572.

13. Woodhead M. Community-acquired pneumonia in Europe: causative pathogens and resistance patterns. Eur Respir J 2002; 20: Suppl. 36, 20s-27s.

14. Dykhuizen RS, Olson ES, Clive $\mathrm{S}$, et al. Necrobacillosis (Lemmiere's syndrome): a rare cause of necrotizing pneumonia. Eur Respir J 1994; 7: $2246-2248$.

15. Sutcliffe J, Tait-Kamradt A, Wondrack L. Streptococcus pneumoniae and Streptococcus pyogenes resistant to macrolides but sensitive to clindamycin: a common resistance pattern mediated by an efflux system. Antimicrob Agents Chemother 1996; 40: 1817-1824.

16. Lonks JR, Garau J, Gomez L, et al. Failure of macrolide antibiotic treatment in patients with bacteremia due to erythromycin-resistant Streptococcus pneumoniae. Clin Infect Dis 2002; 35: 556-564.

17. Waterer GW, Somes GW, Wunderink RG. Monotherapy may be suboptimal for severe bacteremic pneumococcal pneumonia. Arch Int Med 2001; 161: 1837-1842.
18. Office for National Statistics. Mortality Statistics: Deaths registered in England and Wales (Series DR), 2011. www.ons.gov.uk/ons/publications/re-referencetables.html?edition $=$ tcm\%3A77-277727

19. Goldstein B, Giroir B, Randolph A. International pediatric sepsis consensus conference: definitions for sepsis and organ dysfunction in pediatrics. Pediatr Crit Care Med 2005; 6: 2-8.

20. Waterer GW, Quasney MW, Cantor RM, et al. Septic shock and respiratory failure in community-acquired pneumonia have different TNF polymorphism associations. Am J Respir Crit Care Med 2001; 163: 1599-1604.

21. Dremsizov T, Clermont G, Kellum JA, et al. Severe sepsis in community-acquired pneumonia: when does it happen, and do systemic inflammatory response syndrome criteria help predict course? Chest 2006; 129: 968-978.

22. Ranieri VM, Rubenfeld GD, Thompson BT, et al. Acute respiratory distress syndrome: the Berlin Definition. JAMA 2012; 307: 2526-2533.

23. Beutz MA, Abraham E. Community-acquired pneumonia and sepsis. Clin Chest Med 2005; 26: 19-28.

24. Artigas A, Bernard GR, Carlet J, et al. The AmericanEuropean Consensus Conference on ARDS, part 2: Ventilatory, pharmacologic, supportive therapy, study design strategies, and issues related to recovery and remodeling. Acute respiratory distress syndrome. Am J Respir Crit Care Med 1998; 157: 1332-1347.

25. Reynolds HN, McCunn M, Borg U, et al. Acute respiratory distress syndrome: estimated incidence and mortality rate in a 5 million-person population base. Crit Care 1998; 2: 29-34.

26. Dhawan A, Narang A, Singhi S. Hyponatraemia and the inappropriate ADH syndrome in pneumonia. Ann Trop Pediatr 1992; 12: 455-462.

27. Nair V, Niederman MS, Masani N, et al. Hyponatremia in community-acquired pneumonia. Am J Nephrol 2007; 27: 184-190.

28. Ellison DH, Berl T. Clinical practice. The syndrome of inappropriate antidiuresis. N Engl J Med 2007; 356: 2064-2072.

29. Moghal NE, Brocklebank JT, Meadow SR. A review of acute renal failure in children: incidence, etiology and outcome. Clin Nephrol 1998; 49: 91-95.

30. Brandt J, Wong C, Mihm S, et al. Invasive pneumococcal disease and hemolytic uremic syndrome. Pediatrics 2002; 110: 371-376.

31. Waters AM, Kerecuk L, Luk D, et al. Hemolytic uremic syndrome associated with invasive pneumococcal disease: the United kingdom experience. J Pediatr 2007; 151: 140-144.

32. Trompeter RS, Schwartz R, Chantler C, et al. Haemolytic-uraemic syndrome: an analysis of prognostic features. Arch Dis Child 1983; 58: 101-105.

33. Konda S, Zell D, Milikowski C, et al. Purpura fulminans associated with Streptococcus pneumoniae septicemia in an asplenic pediatric patient. Actas Dermosifiliogr 2012 DOI: 10.1016/j.ad.2012.05.009

34. Nilsson IM, Rausing A, Denneberg $T$, et al. Intravascular coagulation and acute renal failure in a child with mycoplasma infection. Acta Med Scand 1971; 189: 359-365.

35. Mirsaeidi M, Peyrani P, Aliberti S, et al. Thrombocytopenia and thrombocytosis at time of hospitalization predict mortality in patients with community-acquired pneumonia. Chest 2010; 137: $416-420$. 
36. Prina E, Ferrer M, Ranzani OT, et al. Thrombocytosis is a marker of poor outcome in community-acquired pneumonia. Chest 2012 [In press DOI: 10.1378/chest.12-1235].

37. Sonnappa S, Jaffe A. Treatment approaches for empyema in children. Paediatr Respir Rev 2007; 8: 164-170.

38. Menzies SM, Rahman NM, Wrightson JM, et al. Blood culture bottle culture of pleural fluid in pleural infection. Thorax 2011; 66: 658-662.

39. Thomas MF, Simmister C, Elemraid MA, Clark JE, Rushton SP, Gorton R, Paton JY, Spencer DA. The UK-ESPE study: paediatric empyema in the UK. Arch Dis Child 2012; 97: A2O-A21.

40. Rees JH, Spencer DA, Parikh D, et al. Increase in incidence of childhood empyema in West Midlands, UK. Lancet 1997; 349: 402.

41. Roxburgh CS, Youngson GG, Townend JA, et al. Trends in pneumonia and empyema in Scottish children in the past 25 years. Arch Dis Child 2008; 93: 316-318.

42. Koshy E, Murray J, Bottle A, et al. Impact of the seven-valent pneumococcal conjugate vaccination (PCV7) programme on childhood hospital admissions for bacterial pneumonia and empyema in England: national time-trends study, 1997-2008. Thorax 2010; 65: 770-774.

43. Thomas MF, Sheppard CL, Guiver M, et al. Emergence of pneumococcal 19A empyema in UK children. Arch Dis Child 2012; 97: 1070-1072.

44. Picazo J, Ruiz-Contreras J, Hernandez B, et al. Clonal and clinical profile of Streptococcus pneumoniae serotype 19A causing pediatric invasive infections: a 2-year (2007-2009) laboratory-based surveillance in Madrid. Vaccine 2011; 29: 1770-1776.

45. Pelton SI, Huot H, Finkelstein JA, et al. Emergence of $19 \mathrm{~A}$ as virulent and multidrug resistant pneumococcus in Massachusetts following universal immunization of infants with pneumococcal conjugate vaccine. Pediatr Infect Dis J 2007; 26: 468-472.

46. AlonsoDeVelasco E, Verheul AF, Verhoef J, et al. Streptococcus pneumoniae: virulence factors, pathogenesis, and vaccines. Microbiol Rev 1995; 59: 591-603.

47. Neeleman C, Geelen SP, Aerts PC, et al. Resistance to both complement activation and phagocytosis in type 3 pneumococci is mediated by the binding of complement regulatory protein factor $\mathrm{H}$. Infect Immun 1999; 67: 4517-4524.

48. McKee AJ, Ives A, Balfour-Lynn IM. Increased incidence of bronchopulmonary fistulas complicating pediatric pneumonia. Pediatr Pulmonol 2011; 46: 717-721.

49. Balfour-Lynn IM, Abrahamson E, Cohen G, et al. BTS guidelines for the management of pleural infection in children. Thorax 2005; 60: Suppl. 1, i1-i21.

50. Jaffe A, Balfour-Lynn IM. Management of empyema in children. Pediatr Pulmonol 2005; 40: 148-156.

51. Ramnath RR, Heller RM, Ben-Ami T, et al. Implications of early sonographic evaluation of parapneumonic effusions in children with pneumonia. Pediatrics 1998; 101: 68-71.

52. Thomson AH, Hull J, Kumar MR, et al. Randomised trial of intrapleural urokinase in the treatment of childhood empyema. Thorax 2002; 57: 343-347.

53. Kearney SE, Davies CW, Davies RJ, et al. Computed tomography and ultrasound in parapneumonic effusions and empyema. Clin Radiol 2000; 55: 542-547.

54. Paksu MS, Paksu S, Akgun M, et al. Bilateral reexpansion pulmonary edema associated with pleural empyema: a case report. Eur J Pediatr 2011; 170: 1205-1207.
55. Ozlu O, Kilic A, Cengizlier R. Bilateral re-expansion pulmonary edema in a child: a reminder. Acto Anaesthesiol Scand 2000; 44: 884-885.

56. Singh M, Mathew JL, Chandra S, et al. Randomized controlled trial of intrapleural streptokinase in empyema thoracis in children. Acta Paediatr 2004; 93: 1443-1445.

57. Barbato A, Panizzolo C, Monciotti C, et al. Use of urokinase in childhood pleural empyema. Pediatr Pulmonol 2003; 35: 50-55.

58. Maskell NA, Davies CW, Nunn AJ, et al. U.K. Controlled trial of intrapleural streptokinase for pleural infection. N Engl J Med 2005; 352: $865-874$.

59. Farjah F, Symons RG, Krishnadasan B, et al. Management of pleural space infections: a population-based analysis. J Thorac Cardiovasc Surg 2007; 133: 346-351.

6o. Davies CW, Kearney SE, Gleeson FV, et al. Predictors of outcome and long-term survival in patients with pleural infection. Am J Respir Crit Care Med 1999; 160: 1682-1687.

61. Rahman NM, Maskell NA, West A, et al. Intrapleural use of tissue plasminogen activator and DNase in pleural infection. N Engl J Med 2011; 365: 518-526.

62. Kern JA, Rodgers BM. Thoracoscopy in the management of empyema in children. J Pediatr Surg 1993; 28: $1128-1132$

63. Kern L, Robert J, Brutsche M. Management of parapneumonic effusion and empyema: medical thoracoscopy and surgical approach. Respiration 2011; 82: 193-196.

64. Subramaniam R, Joseph VT, Tan GM, et al. Experience with video-assisted thoracoscopic surgery in the management of complicated pneumonia in children. J Pediatr Surg 2001; 36: 316-319.

65. Kurt BA, Winterhalter KM, Connors $\mathrm{RH}$, et al. Therapy of parapneumonic effusions in children: videoassisted thoracoscopic surgery versus conventional thoracostomy drainage. Pediatrics 2006; 118: e547-e553.

66. St Peter SD, Tsao K, Spilde TL, et al. Thoracoscopic decortication vs tube thoracostomy with fibrinolysis for empyema in children: a prospective, randomized trial. J Pediatr Surg 2009; 44: 106-111.

67. Gates RL, Hogan M, Weinstein S, et al. Drainage, fibrinolytics, or surgery: a comparison of treatment options in pediatric empyema. J Pediatr Surg 2004; 39: $1638-1642$.

68. Sonnappa S, Cohen G, Owens CM, et al. Comparison of urokinase and video-assisted thoracoscopic surgery for treatment of childhood empyema. Am J Respir Crit Care Med 2006; 174: 221-227.

69. Bishay M, Short M, Shah K, et al. Efficacy of videoassisted thoracoscopic surgery in managing childhood empyema: a large single-centre study. J Pediatr Surg 2009; 44: 337-342.

70. Cohen E, Weinstein M, Fisman DN. Cost-effectiveness of competing strategies for the treatment of pediatric empyema. Pediatrics 2008; 121: e1250-e1257.

71. Roberts JE, Bezack BJ, Winger DI, et al. Association between parapneumonic effusion and pericardial effusion in a pediatric cohort. Pediatrics 2008; 122: e1231-e1235.

72. Donnelly LF, Klosterman LA. The yield of CT of children who have complicated pneumonia and noncontributory chest radiography. AJR Am J Roentgenol 1998; 170: 1627-1631.

73. Dass R, Deka NM, Barman H, et al. Empyema thoracis: analysis of 150 cases from a tertiary care centre in North East India. Ind J Pediatr 2011; 78: 1371-1377. b) are primarily caused by Gram-positive organisms

c) can be diagnosed on chest radiography in 90\% of cases

d) Ultrasound scan is the most useful radiological test

e) can be a primary presentation of a congenital thoracic malformation

4) Necrotising

pneumonia

a) complicates up to $20 \%$ of childhood empyema

b) is predominantly caused by Staphylococcus aureus

c) Pneumatocoeles are small pneumothoraces

d) may require surgical intervention in twothirds of cases

e) Fibrinolytics may be used to aid drainage of necrotic lung parenchyma

5) Further investigations

a) should be undertaken routinely in all children who present with empyema

b) Flexible bronchoscopy can be both diagnostic and therapeutic

c) Exhaled nitric oxide is a screening test for primary ciliary dyskinesia

d) Video fluoroscopy can demonstrate gastrooesophageal reflux disease

e) Congenital heart disease may predispose to recurrent pneumonia in infants 


\section{Suggested}

\section{answers}
1) c and e
2) a and e
3) a and e
4) a and $d$
5) b and e

74. Kendig EL, Wilmott RW, Kendig and Chernick's Disorders of the Respiratory Tract in Children. 8th Edn. Philadelphia: Saunders/Elsevier; 2012.

75. Evans DA, Fiedler MA. Lung abscess in a patient with cystic fibrosis: case report and review of the literature. Pediatr Pulmonol 1996; 21: 337-340.

76. Canny GJ, Marcotte JE, Levison H. Lung abscess in cystic fibrosis. Thorax 1986; 41: 221-222.

77. Patradoon-Ho P, Fitzgerald DA. Lung abscess in children. Paediatr Respir Rev 2007; 8: 77-84.

78. Chan PC, Huang LM, Wu PS, et al. Clinical management and outcome of childhood lung abscess: a 16year experience. J Microbiol Immunol Infect 2005; 38: 183-188.

79. Leonardi S, del Giudice MM, Spicuzza L, et al. Lung abscess in a child with Mycoplasma pneumoniae infection. Eur J Pediatr 2010; 169: 1413-1315.

80. Hogan MJ, Coley BD. Interventional radiology treatment of empyema and lung abscesses. Paediatr Respir Rev 2008; 9: 77-84.

81. Tan TQ, Seilheimer DK, Kaplan SL. Pediatric lung abscess: clinical management and outcome. Pediatr Infect Dis J 1995; 14: 51-55.

82. Asher MI, Spier S, Beland M, et al. Primary lung abscess in childhood: the long-term outcome of conservative management. Am J Dis Child 1982; 136: 491-494.

83. Kosloske AM, Ball WS Jr, Butler C, et al. Drainage of pediatric lung abscess by cough, catheter, or complete resection. J Pediatr Surg 1986; 21: 596-600.

84. Tseng YL, Wu MH, Lin MY, et al. Surgery for lung abscess in immunocompetent and immunocompromised children. J Pediatr Surg 2001; 36: 470-473.

85. Nagasawa KK, Johnson SM. Thoracoscopic treatment of pediatric lung abscesses. J Pediatr Surg 2010; 45: $574-578$

86. Kerem E, Bar Ziv Y, Rudenski B, et al. Bacteremic necrotizing pneumococcal pneumonia in children. Am J Respir Crit Care Med 1994; 149: 242-244.
87. Sawicki GS, Lu FL, Valim C, et al. Necrotising pneumonia is an increasingly detected complication of pneumonia in children. Eur Respir J 2008; 31: 1285-1291.

88. Ramphul N, Eastham KM, Freeman R, et al. Cavitatory lung disease complicating empyema in children. Pediatr Pulmonol 2006; 41: 750-753.

89. Hsieh YC, Hsiao CH, Tsao PN, et al. Necrotizing pneumococcal pneumonia in children: the role of pulmonary gangrene. Pediatr Pulmonol 2006; 41: 623-629.

90. Hodina M, Hanquinet S, Cotting J, et al. Imaging of cavitary necrosis in complicated childhood pneumonia. Eur Radiol 2002; 12: 391-396.

91. Knight G), Carman PG. Primary staphylococcal pneumonia in childhood: a review of 69 cases. J Paediatr Child Health 1992; 28: 447-450.

92. Wang RS, Wang SY, Hsieh KS, et al. Necrotizing pneumonitis caused by Mycoplasma pneumoniae in pediatric patients: report of five cases and review of literature. Pediatr Infect Dis J 2004; 23: 564-567.

93. Labandeira-Rey M, Couzon F, Boisset $\mathrm{S}$, et al. Staphylococcus aureus Panton-Valentine leukocidin causes necrotizing pneumonia. Science 2007; 315: 1130-1133.

94. Hacimustafaoglu M, Celebi S, Sarimehmet $\mathrm{H}$, et al. Necrotizing pneumonia in children. Acta Paediatr 2004; 93: 1172-1177.

95. Parikh DH, Crabbe D, Auldist A, et al., eds Pediatric Thoracic Surgery. London: Springer, 2009.

96. Lukrafka JL, Fuchs SC, Fischer GB, et al. Chest physiotherapy in paediatric patients hospitalised with community-acquired pneumonia: a randomised clinical trial. Arch Dis Child 2012; 97: 967-971.

97. Liang $Y$, Liu XC, Jiang QB. [Role of flexible bronchoscopy in the treatment of infection-associated atelectasis in children]. Chin J Pediatr 2003; 41: 649-651. 